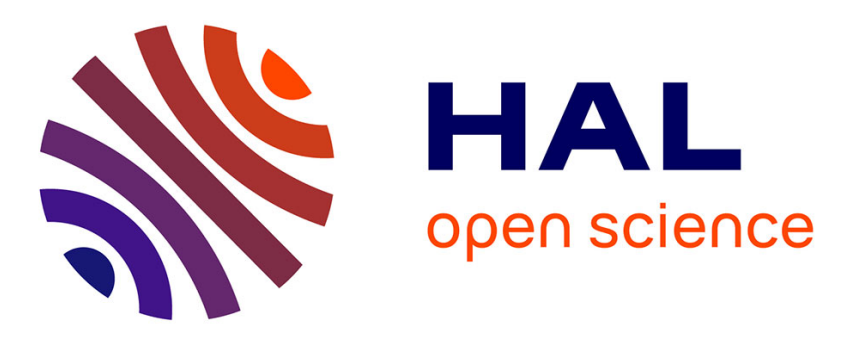

\title{
Multimodality approach in extra cervical locally advanced cervical cancer: chemoradiation, surgery and intraoperative radiation therapy. a phase II trial
}

\author{
G. Giorda, G. Boz, A. Gadducci, E. Lucia, G. de Piero, A. de Paoli, R. \\ Innocente, M. Trovò, R. Sorio, E. Campagnutta
}

\section{To cite this version:}

G. Giorda, G. Boz, A. Gadducci, E. Lucia, G. de Piero, et al.. Multimodality approach in extra cervical locally advanced cervical cancer: chemoradiation, surgery and intraoperative radiation therapy. a phase II trial. EJSO - European Journal of Surgical Oncology, 2011, 37 (5), pp.442. 10.1016/j.ejso.2011.02.011 . hal-00687019

\section{HAL Id: hal-00687019 https://hal.science/hal-00687019}

Submitted on 12 Apr 2012

HAL is a multi-disciplinary open access archive for the deposit and dissemination of scientific research documents, whether they are published or not. The documents may come from teaching and research institutions in France or abroad, or from public or private research centers.
L'archive ouverte pluridisciplinaire HAL, est destinée au dépôt et à la diffusion de documents scientifiques de niveau recherche, publiés ou non, émanant des établissements d'enseignement et de recherche français ou étrangers, des laboratoires publics ou privés. 


\section{Accepted Manuscript}

Title: Multimodality approach in extra cervical locally advanced cervical cancer: chemoradiation, surgery and intraoperative radiation therapy. a phase II trial

Authors: G. Giorda, M.D. G. Boz, M.D. A. Gadducci, M.D. E. Lucia, M.D. G. De Piero, M.D. A. De Paoli, M.D. R. Innocente, M.D. M. Trovò, M.D. R. Sorio, M.D. E.

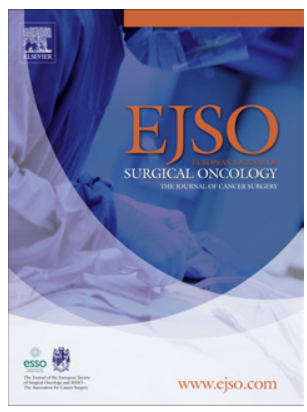
Campagnutta, M.D.

PII: S0748-7983(11)00082-5

DOI: 10.1016/j.ejso.2011.02.011

Reference: $\quad$ YEJSO 3134

To appear in: European Journal of Surgical Oncology

Received Date: 2 July 2010

Revised Date: 18 December 2010

Accepted Date: 28 February 2011

Please cite this article as: Giorda G, Boz G, Gadducci A, Lucia E, De Piero G, De Paoli A, Innocente R, Trovò M, Sorio R, Campagnutta E. Multimodality approach in extra cervical locally advanced cervical cancer: chemoradiation, surgery and intraoperative radiation therapy. a phase II trial, European Journal of Surgical Oncology (2011), doi: 10.1016/j.ejso.2011.02.011

This is a PDF file of an unedited manuscript that has been accepted for publication. As a service to our customers we are providing this early version of the manuscript. The manuscript will undergo copyediting, typesetting, and review of the resulting proof before it is published in its final form. Please note that during the production process errors may be discovered which could affect the content, and all legal disclaimers that apply to the journal pertain. 
1 MULTIMODALITY APPROACH IN EXTRA CERVICAL LOCALLY ADVANCED CERVICAL 2 CANCER: CHEMORADIATION, SURGERY AND INTRAOPERATIVE RADIATION 3 THERAPY. A PHASE II TRIAL

$4 \quad$ G. Giorda M.D. ${ }^{\text {a }}$, ggiorda@cro.it

$5 \quad$ G. Boz M.D. b, gboz@cro.it

$6 \quad$ A. Gadducci M.D. ${ }^{\text {c }}$, a.gadducci@obgyn.med.unipi.it

$7 \quad$ E. Lucia M.D. ${ }^{\text {a }}$, elucia@cro.it

$8 \quad$ G. De Piero M.D. ${ }^{a}$, gdepiero@cro.it

$9 \quad$ A. De Paoli M.D. ', adepaoli@cro.it

R. Innocente M.D. ${ }^{b}$, rinnocente@cro.it

11 M. Trovò M.D. ${ }^{b}$, mtrovo@cro.it

R. Sorio M.D. ${ }^{d}$, rsorio@cro.it

E. Campagnutta M.D. ${ }^{a}$ ecampagnutta@cro.it

14 from the Centro di Riferimento Oncologico (C.R.O) - I.R.C.S.S..

National Cancer Institute (a)Gynecologic Oncology Unit, (b) Radiotherapy Unit, (d) Clinical Oncology Unit, Via Franco Gallini 2, 33081 Aviano (PN), Italy and from (c) University of Pisa Gynecologic and Obstetrics Clinic Corresponding Author: Giorgio Giorda MD;

19 CRO via Franco Gallini 2, 33081 Aviano (PN) Italy;

20 Phone: +39-0434-657037 Fax: +39-0434-657049

21 e-mail: ggiorda@cro.it 
BACKGROUND. The goal of this study was to determine the rational of radical surgery with intraoperative high-dose radiotherapy after chemoradiation (RT-CT) in extra cervical locally advanced cervical cancer (LACC) patients.

METHODS. Between 2000 and 2007, 42 LACC (stage IIA bulky-IVA) patients were treated at the Gynecologic Oncology Unit of the C.R.O. of Aviano in a Phase II Clinical Trial. Radiotherapy was administered to the whole pelvic region ( 50.4 Gy in 28 fractions) in combination with cisplatin $(60 \mathrm{mg} / \mathrm{mq})$ plus $5 \mathrm{FU}(750 \mathrm{mg} / \mathrm{mq}$ for 4 days $)$ on first and fifth week of RT. Radical surgery with Intra-Operative Radiation Therapy (IORT) was performed 6-8 weeks after the end of RT-CT treatment.

RESULTS. After RT-CT, 35/42 patients (83\%) underwent radical surgery and IORT treatment. At pathologic examination 8/35 (23\%) patients showed complete response, while the rest (27/35) had residual disease either microscopic (17/27) or gross (10/27). The 5-year disease free survival (DFS) and the 5-year overall survival (OS) were $46 \%$ and $49 \%$ respectively. There were significant better DFS and OS when residual tumor was absent or limited to the cervix, respectively $78 \%$ versus $16 \%$ and $81 \%$ versus $20 \%$ (p $<0.001)$. All recurrences occurred within 24 months from treatment.

CONCLUSIONS. RT-CT followed by surgery and IORT in LACC patients seems to be active in a subgroup of patients with pathological complete response to treatment or partial response with residual tumor limited to the cervix.

KEYWORDS: Uterine Cervical neoplasms; Locally Advanced; Chemotherapy; Sugery; Intra-operative Radiotherapy; Combined Modality Therapy

ABBREVIATIONS: Intra-Operative Radiation Therapy (IORT); in-field recurrence(IFR); out-field recurrence (OFR) 


\section{INTRODUCTION}

51

52

53

54

55

56

57

Cervical cancer is the second most frequent cancer for mortality worldwide, due to late diagnosis in developing countries, and the associated mortality [1] correlates with the stage of the disease [2]. Nowadays, concomitant Radiotherapy and Cisplatin based chemotherapy is the standard treatment for locally advanced cases of cervical cancer (LACC, stage IB2-IVA) [3-5] .

Indeed, a meta-analysis of 13 randomised trials confirmed that concurrent chemoradiation significantly improved disease-free survival, locoregional recurrence-free survival, metastasis-free survival and overall survival compared with irradiation alone [6,7]. Also, there was a suggestion of a difference in the survival benefit with tumour stage, but not across other patient subgroups. Furthermore, neoadjuvant chemotherapy followed by radical hysterectomy contributed to satisfactory results in LACC [8-14] and a meta-analysis of 5 randomised trials showed that this treatment modality was superior to irradiation alone presenting a gain in the 5-year overall survival of 14\% [11] [15]. Finally, in an Italian randomised trial, chemo-surgical treatment achieved better progression-free and overall survival compared with irradiation alone in patients with stage Ib2-Ilb disease, whereas there was no significant difference in the clinical outcome between these two treatment modalities in patients with stage III_disease [12]. Actually, one of the main objectives of current research in LACC is to improve the response rate either by modifying the treatment schedule of chemoradiation or by using neoadjuvant chemoradiation followed by surgery [16-19].

To this aim, a multimodality treatment approach on women with extra cervical LACC (stage IIA bulky-IVA) was tested in a Phase II trial including neoadjuvant chemoradiation followed by radical surgery and Intra-Operative Radiation Therapy (IORT) in this clinical setting. 


\section{PATIENTS AND METHODS}

78

79

80

81

\section{Study}

From January 2000 to January 2007, 42 extra cervical LACC patients with biopsy-proven carcinoma of the cervix entered a Phase II Clinical Trial on the role of surgery and IORT after concomitant chemoradiation. Inclusion criteria were: stage IIA-Bulky $(>4 \mathrm{~cm})$ to stage IVA disease, no evidence of disease outside the pelvis; age <75years; Eastern Cooperative Oncology Group performance status <2; adequate bone-marrow function (WBC $>3000 / \mathrm{mm}^{3}$, platelets $>150,000 / \mathrm{mm}^{3}$ ); normal liver function (blood bilirubin $<2 \mathrm{mg} / \mathrm{dl}$ ); adequate renal function (blood urea nitrogen $<25 \mathrm{mg} / \mathrm{dl}$ ) and no prior cancer. All patients signed a written informed consent to participate to the experimental protocol approved by Local Research Ethics Committee.

Before accrual, the patients underwent history and clinical examination, gynecological examination, complete blood count, biochemical workup abdomino-pelvic CT scan (to exclude extra pelvic disease) and pelvic MRI (to measure the volume of pelvic neoplasia). Cystoscopy and sigmoidoscopy were performed in the case of clinical suspicion of bladder or rectal involvement.

\section{Treatment Schedule}

Treatment started with external beam radiotherapy, 4-field technique, 50.4 Gy in 28 fractions (on the pelvic field up to common iliac nodes included) and concurrent chemotherapy consisted of intravenous infusion of cisplatin $60 \mathrm{mg} / \mathrm{m}^{2}$ on day 1 plus 5 fluorouracil $750 \mathrm{mg} / \mathrm{m}^{2}$ on days $2-5$ during the first and fifth weeks of radiotherapy. Chemotherapy was administered when leukocyte count was greater than $3000 / \mathrm{mm}^{3}$, platelet count greater than $150,000 / \mathrm{mm}^{3}$ and serum creatinine level less than $1.5 \mathrm{mg} / \mathrm{dl}$. 
101 Toxicity was evaluated in all patients. No patients received pre-operative brachytherapy. 102 Physical and vaginal- pelvic examination together with abdominal-pelvic MRI were repeated 4 weeks after the end of concomitant chemoradiation for the evaluation of clinical response (according to RECIST criteria [20]) and for the planning of surgical treatment. After chemoradiation, laparotomic radical hysterectomy and pelvic lymphadenectomy were performed. If common iliac nodes were positives at frozen section, para-aortic lymphadenectomy below the level of inferior mesenteric artery was also performed. Pelvic exenteration was performed in the presence of bladder involvement. At the end of surgery and before abdomen closure IORT was delivered on bilateral pelvic sites, including the surgical resection margin of parametrium, the obturator fossa and external pelvic vessels. Monolateral delivery of IORT was performed if neoplasia was clearly expanding monolateraly with negative frozen-section in contralateral site. Other sites of pelvis and aortic lymphnodes were irradiated with IORT if the tissue removed was suspect at macroscopic inspection and confirmed at frozen-section. If ureters had to be freed from a cuff of neoplastic tissue (evaluated at frozen section), a pig-tail stent was inserted and ureters were included in IORT irradiation. IORT irradiation sites were marked with metallic clips larger than those utilized for lymphadenectomy in order to distinguish in-field from out-field pelvic recurrences. Complications were defined as intra-operative (bladder, ureter, bowel, vascular or nerve injuries and blood loss exceeding $500 \mathrm{ml}$ ), peri-operative (within 30 days from surgery) and post-operative (after 30 days from surgery), and described according to Chassagne [21]. Three different categories of pathological responses were determined: complete response (no evidence of tumor), partial microscopic response (only microscopic foci) and partial macroscopic response (gross persistent disease). Partial microscopic or macroscopic responses were classified by either only cervical or outside the cervix (parametrium, lymph nodes and pelvic tissue).

\section{Follow-up}

Postoperative management was individually established on the basis of histological findings on surgical samples, patient age and general conditions, after discussion of the options with the patient 
132 Patients were periodically followed up with physical and gynecological examination, complete blood count and blood chemistry every 3 months for the first two years and every six months thereafter. Pelvic MRI and abdominal CT were performed every 6 months for the first two years and every 12 months thereafter.

Pelvic recurrences were classified as in-field (IFR) or out-field (OFR) if they occurred 137 within or outside the IORT irradiation field. Distant recurrences (DR) were noted if they 138 occurred outside the pelvis.

139 Statistics

140 Chi-square test was used for discrete and binomial data. Progression-free and overall 141 survivals were estimated by the product limit method of Kaplan and Meier, and survival 142 curves were compared using the log-rank test. Cox's proportional hazard regression model 143 was used to assess the relationship between survival data and covariates. Difference was 144 considered significant if $P<0.05$. Disease free survival (DFS) and overall survival (OS) 145 were calculated from the date of surgery to the date of relapse and to the date of death or 146 last follow-up, respectively. 


\section{Chemoradiation Treatment}

The clinical-radiological reassessment after the end of concomitant chemoradiation showed a clinical complete response in 2/42 (5\%) patients, and a partial response in 23/42 $(54 \%)$, with an overall response rate of $59 \%$. Toxicity due to chemoradiation was evaluated in all 42 patients. Hematological toxicity was grade 1-2 in 38 patients $(90 \%)$ and grade 3-4 in 2 (5\%). Grade 1-2 and grade 3-4 gastrointestinal toxicity occurred in 22 (52\%) and $5(12 \%)$ patients, respectively. Two patients developed grade 1-2 neurotoxicity (5\%).

\section{Surgical Treatment}

Four out of the 42 initial women did not undergo surgery, three because of disease progression and one for refusal. Of the 38 patients who underwent surgery, after a median of 38 days (range from 15 to 73 ) from the completion of chemoradiation, three did not receive radical surgery because of unresactable tumor extended to pelvic wall (two patients) or massive intraoperative hemorrhage (one patient). Thirty-five women underwent laparotomic radical hysterectomy (classified according to Piver's nomenclature) with pelvic lymphadenectomy: $5(14 \%)$ had type 2 radical hysterectomy, $21(60 \%)$ had type 3 radical hysterectomy, 6 (17\%) type $4-5$ radical hysterectomy, and $3(9 \%)$ had anterior exenteration. Systematic pelvic lymphadenectomy was performed in all patients with a mean of 19.8 lymph nodes removed (range from 12 to 31). Para-aortic lymphadenectomy was performed in 7 patients with a mean of 6 lymph nodes (range from 3 to 9 ). The mean operative time duration was 303 minutes (range from 230 to 490).

\section{IORT Treatment}

The characteristics of the 35 patients that completed the planned combined treatment RTCT followed by surgery and IORT are reported on Table 1. IORT was delivered to bilateral pelvic wall in $29(82.9 \%)$ patients, to mono-lateral pelvic wall in $4(11.3 \%)$, to bilateral pelvic wall and central pelvis in one patient $(2.9 \%)$ and to bilateral pelvic wall and para- 
aortic area in one patient (2.9\%). As far as IORT is concerned, the mean delivered dose was 11 Gy (range from 10 to $15 \mathrm{~Gy}$ ) and mean diameter of irradiation field was $6.3 \mathrm{~cm}$ (range from 5.7 to $8.3 \mathrm{~cm}$ ).

\section{Complications}

The only major intraoperative complication was the section of the right obturator nerve infiltrated by a massively enlarged lymph node. The nerve was repaired immediately with no sequelae. Twelve patients had an intraoperative blood loss greater than $500 \mathrm{ml}$ and 8 of them required blood transfusion. In one patient an intraoperative hemorrhage did not allow radical surgery and the delivery of the scheduled IORT. Peri-operative and postoperative complications are reported in Table 2. Mono-or bilateral ureteral stents were placed in 7 patients. Five of them had undergone a pre-operative nephrostomy for the presence of hydronephrosis, whereas in 2 patients a pig tail stent was inserted after the ureter was freed from fibrotic tissue with injury of ureteral serosa. Only one ureter was included in IORT field. Three patients who underwent anterior exenteration had their ureters sectioned on tumor-free tissue and were not included in IORT field. All three ureteral fistulae occurred in the first 12 patients when we used to insert the stents through ureteral incision. Because of this complication, subsequently catheters were_inserted through cystostomy. Deep venous thrombosis, developed in $9 \%$ of the patients, were managed with high dosage of low molecular weight heparin without any embolic complications (assessed by lung CT and scintigraphy). 
199 The mean hospital stay was 22.1 days (range from 9 to 89). Five patients with long term 200 hospital stay were discharged and re-admitted many times for treatment-related 201 complications.

202

\section{Pathological Findings}

Pathological findings are reported on Table 3. No patient had positive surgical margins. In patients with microscopic cervical residue only $4 / 14$ of them (28.6\%) had residual infiltration of less than $5 \mathrm{~mm}$ from surface of cervical epithelium; none of these four women had residual disease outside cervix. The others 10 patients had multiple foci of residual tumor throughout the cervical stroma; five of them (50\%) had also positive parametrium. Nine patients $(26 \%)$ had positive pelvic nodes within field of pre-surgical irradiation. Three out of seven (43\%) patients with para-aortic lymphadenectomy had positive aortic nodes, and one had positive inguinal nodes.

\section{Post-operative treatment}

Post-operative adjuvant treatment consisted of vaginal brachitherapy in 4 patients, chemotherapy with different agents in 8 patients, and brachitherapy plus chemotherapy in one patient.

\section{Follow-up}

At the time of the present analysis, 17/35 (48\%) patients were alive but developed a relapse with a median of 22 months and 15/35 (43\%) patients died of disease with a median of 33 months; $3 / 35$ (9\%) patients were alive and free of disease.

Recurrent disease was pelvic in 10 patients, pelvic plus distant in 3 (one in the lung and two in aortic nodes), and distant alone in 4 (one in the lung, two in para-aortic nodes, one in neck nodes). As far as the 13 pelvic failures are concerned, 4 recurrences were IFR and 9 were OFR.

As a whole, 4 out of $35(11 \%)$ patients with Locally Advanced Cervical Cancer (LACC) and treated with IORT experienced an IFR. All the recurrences occurred within 24 months. 
227 Three of the 15 significantly, due to septic pelvic complications, were computed as 228 disease related.

229 Statistical Evaluation

230 In the group of 35 patients treated with radical surgery and IORT, 5-year DFS and 5-year 231 OS were $46 \%$ and $49 \%$, respectively ( Figure 1 for OS) with significantly better OS in 232 patients with no residual disease or disease limited to cervix after chemoradiation.

233 Both in univariate (log-rank test) and multivariate analysis (Cox proportional hazard model) 234 DFS and OS were significantly associated only with residual disease outside the cervix: $235 \mathrm{HR}=0.13(95 \% \mathrm{Cl}=0.04-0.44, \mathrm{p}<0.002)$ and $\mathrm{HR}=0.15(95 \% \mathrm{Cl} 0.03-0.65, \mathrm{p}<0.02)$ 236 respectively. Stage ( $\geq$ Stage 2 ), age (more or less than 50 years), and tumor diameter 237 (greater or less than $4 \mathrm{~cm}$ ) were not significantly correlated with DFS and OS (data not 238 shown). These figures were similar both in the whole group of 42 patients with the 239 intention to treat analysis and in the group of 35 patients who underwent radical surgery 240 and IORT. 


\section{DISCUSSION}

Concurrent chemoradiation represents the gold standard for the treatment of patients with LACC[22]. However, further clinical investigation is strongly recommended to identify new treatment strategies aimed to maximize the local control and to improve overall survival. In this context, the integrated use of three-modality treatment (radiotherapy, chemotherapy and surgery) was tested in this clinical setting [18,23-25]. Some authors have also added IORT procedure in their treatment protocol [26]. Several studies have enrolled a variable proportion of stage lb2 patients, a sub-set of advanced cervical cancer that usually experience a more favorable prognosis than women with extra cervical extension of disease. Therefore in the present study we decided to recruit only patients with extracervical tumor (and a less favorable prognosis within all LACC patients) to test if a multimodality treatment including IORT could improve both local control and long-term clinical outcome. Our set of patients includes both stage II cancers, for whom the standard treatment is exclusive concomitant chemoradiation, and stage III patients for whom different treatment approaches seem to have similar dismal results [12, 27] although a recent paper[19] seems to disclose new perspectives in stage III patients treated with surgery following neo-adjuvant chemoradiation.

\section{Complications}

Both chemoradiation related side effects and intra-operative complications were acceptable and comparable to those reported in the literature $[5,23]$. Less than $12 \%$ of women experienced a grade 3-4 toxicity due to chemoradiation, $23 \%$ had a blood loss requiring transfusion, and one woman had obturator nerve section. On the other hand, peri-and post-operative complication rates were relatively high, especially as far as lymphocele $(21 \%)$, pelvic sepsis $(14 \%)$, ureteral fistulae $(8 \%)$ and deep venous thrombosis $(9 \%)$. The mean hospital stay was of 22 days, in excess of that reported by other authors in comparable surgical settings [18]. This long hospital stay was due to treatment complications and to the fact that patients were not discharged until lymphorrhea from drainage was less than $100 \mathrm{ml}$ per day. Three of the 15 deaths were due to septic pelvic complications but were attributed to the disease in survival calculations. The high rate of surgery-related complications is due to the combination of high radiation dose and aggressive surgery, in agreement with the data of Houvenaeghel et al. [28] who reported a 

305 306

complication rate of $32 \%$ after radical hysterectomy compared with $12 \%$ after simple hysterectomy.

\section{Response characteristics}

In our population, the clinical overall response rate to chemoradiation was $59 \%$, and the optimal pathological (complete plus partial microscopic) response rate was $45.8 \%$, slightly lower than that reported following chemoradiation $(61-73 \%)$ by other authors $[23,25,28]$. The different pathological response rates may be partly dependent on the heterogeneity of patient populations and treatment modalities [18,23,25,28]. In our study, the extended pelvic field external irradiation dosage was 10-20\% higher, and cisplatin dose intensity was $25-40 \%$ lower when compared to those used by other authors, and brachytherapy was not administered. Moreover, patients with stage lb2 cervical cancer were not included in the present analysis, and the overall survival was unsatisfactory, albeit similar to that observed for a comparable group (stage II - IV) of patients treated with chemoradiation only in GOG 120 and GOG 165 trials [27]. The only significant variable influencing recurrence rate and survival was the presence of residual tumor outside the cervix (Figure 1 for OS) irrespective of the amount of cervical residue. The subset of 15 patients (43\%) with residual tumor only within the cervix had an excellent prognosis, with 5-year cumulative survival higher than $80 \%$. On the other hand, the 20 patients with extra-cervical tumor residue had a dismal clinical outcome, irrespective of site of residual disease (either pelvic nodes or parametrial-vaginal tissue), with a 3-year cumulative survival of only $24 \%$. It is possible that aortic lymph nodes positivity could influence the survival figures, although all the patients were selected for absence of disease outside the pelvis by pretreatment imaging.

\section{Prognostic Factors}

Therefore, the persistence of extra cervical residual disease after chemoradiation, even if surgically removed, is a poor prognostic factor. Although IORT improves local control of neoplasia (IFR are only $11.4 \%$ of total recurrences), local control of neoplasia does not contribute to overall survival, that is dismal in this set of patients with extra cervical LACC. It is possible that patients without residual disease outside the cervix could be conveniently treated with brachytherapy following chemoradiation as well.

\section{Outlook}


307 It seems that extra cervical LACC is not a local neoplasia any more. So the intensification 308 of concurrent chemotherapy regimen (increased cisplatin dose intensity) in chemoradiation 309 protocols and especially a more accurate selection of patients who could benefit from this 310 combined treatment are strongly recommended for future studies in order to improve the 311 clinical outcome and to minimize complications.

\section{CONFLICT OF INTEREST STATEMENT}

317 There is no direct financial interest with any company in this trial, that was supported only 318 by Centro di Riferimento Oncologico (C.R.O) - I.R.C.S.S 
1. Lin SS, Clarke CA, Prehn AW et al.: Survival differences among Asian subpopulations in the United States after prostate, colorectal, breast, and cervical carcinomas. Cancer 2002: 94:1175-1182.

2. Coker AL, Du XL, Fang S, Eggleston KS: Socioeconomic status and cervical cancer survival among older women: findings from the SEER-Medicare linked data cohorts. Gynecol Oncol 2006: 102:278-284.

3. Rose PG, Bundy BN, Watkins EB et al.: Concurrent cisplatin-based radiotherapy and chemotherapy for locally advanced cervical cancer. N Engl J Med 1999: 340:1144-1153.

4. Rose PG: Combined-modality therapy of locally advanced cervical cancer. J Clin Oncol 2003: 21:211s-217s.

5. Lanciano R, Calkins A, Bundy BN et al.: Randomized comparison of weekly cisplatin or protracted venous infusion of fluorouracil in combination with pelvic radiation in advanced cervix cancer: a gynecologic oncology group study. J Clin Oncol 2005: 23:8289-8295.

6. Green J, Kirwan J, Tierney J et al.: Concomitant chemotherapy and radiation therapy for cancer of the uterine cervix. Cochrane Database Syst Rev 2005:CD002225.

7. Green JA, Kirwan JM, Tierney JF et al.: Survival and recurrence after concomitant chemotherapy and radiotherapy for cancer of the uterine cervix: a systematic review and meta-analysis. Lancet 2001: 358:781-786.

8. Sardi JE, Giaroli A, Sananes C et al.: Long-term follow-up of the first randomized trial using neoadjuvant chemotherapy in stage lb squamous carcinoma of the cervix: the final results. Gynecol Oncol 1997: 67:61-69.

9. Benedetti-Panici P, Greggi S, Scambia G et al.: Long-term survival following neoadjuvant chemotherapy and radical surgery in locally advanced cervical cancer. Eur J Cancer 1998: 34:341-346.

10. Neoadjuvant chemotherapy for locally advanced cervix cancer. Cochrane Database Syst Rev 2004:CD001774.

11. Gonzalez-Martin A, Gonzalez-Cortijo L, Carballo $\mathrm{N}$ et al.: The current role of neoadjuvant chemotherapy in the management of cervical carcinoma. Gynecol Oncol 2008: 110:S36-S40.

12. Benedetti-Panici $P$, Greggi S, Colombo A et al.: Neoadjuvant chemotherapy and radical surgery versus exclusive radiotherapy in locally advanced squamous cell cervical cancer: results from the Italian multicenter randomized study. J Clin Oncol 2002: 20:179-188. 
13. Buda $\mathrm{A}$, Fossati $\mathrm{R}$, Colombo $\mathrm{N}$ et al.: Randomized trial of neoadjuvant chemotherapy comparing paclitaxel, ifosfamide, and cisplatin with ifosfamide and cisplatin followed by radical surgery in patients with locally advanced squamous cell cervical carcinoma: the SNAP01 (Studio Neo-Adjuvante Portio) Italian Collaborative Study. J Clin Oncol 2005: 23:4137-4145.

14. Lissoni AA, Colombo N, Pellegrino A et al.: A phase II, randomized trial of neo-adjuvant chemotherapy comparing a three-drug combination of paclitaxel, ifosfamide, and cisplatin (TIP) versus paclitaxel and cisplatin (TP) followed by radical surgery in patients with locally advanced squamous cell cervical carcinoma: the Snap-02 Italian Collaborative Study. Ann Oncol 2009: 20:660-665.

15. Tierney J, Neoadjuvaant Chemotherapy for Cervical Cancer Meta-analysis Collaboration: Neoadjuvant chemotherapy for locally advanced cervical cancer: a systematic review and meta-analysis of individual patient data from 21 randomised trials. Eur J Cancer 2003: 39:2470-2486.

16. Tsuda H, Tanaka M, Manabe T et al.: Phase I-II study of neoadjuvant chemoradiotherapy followed by radical surgery in locally advanced cervical cancer. Anticancer Drugs 2001: 12:853-858.

17. Shibata K, Kikkawa F, Suzuki Y et al.: Usefulness of preoperative chemoradiation in locally advanced cervical carcinoma. Gynecol Obstet Invest 2004: 57:93-99.

18. Classe JM, Rauch P, Rodier JF et al.: Surgery after concurrent chemoradiotherapy and brachytherapy for the treatment of advanced cervical cancer: morbidity and outcome: results of a multicenter study of the GCCLCC (Groupe des Chirurgiens de Centre de Lutte Contre le Cancer). Gynecol Oncol 2006: 102:523-529.

19. Fanfani F, Fagotti A, Ferrandina G et al.: Neoadjuvant chemoradiation followed by radical hysterectomy in FIGO Stage IIIB cervical cancer: feasibility, complications, and clinical outcome. Int J Gynecol Cancer 2009: 19:1119-1124.

20. Therasse P, Arbuck SG, Eisenhauer EA et al.: New guidelines to evaluate the response to treatment in solid tumors. European Organization for Research and Treatment of Cancer, National Cancer Institute of the United States, National Cancer Institute of Canada. J Natl Cancer Inst 2000: 92:205-216.

21. Chassagne D, Sismondi P, Horiot JC et al.: A glossary for reporting complications of treatment in gynecological cancers. Radiother Oncol 1993: 26:195-202.

22. Green J, Kirwan J, Tierney J et al.: Concomitant chemotherapy and radiation therapy for cancer of the uterine cervix. Cochrane Database Syst Rev 2005:CD002225.

23. Ferrandina G, Legge F, Fagotti $A$ et al.: Preoperative concomitant chemoradiotherapy in locally advanced cervical cancer: safety, outcome, and prognostic measures. Gynecol Oncol 2007: 107:S127-S132.

24. Houvenaeghel $G$, Lelievre L, Gonzague-Casabianca $L$ et al.: Long-term survival after concomitant chemoradiotherapy prior to surgery in advanced cervical carcinoma. Gynecol Oncol 2006: 100:338-343. 
25. Huguet $F$, Cojocariu OM, Levy $P$ et al.: Preoperative concurrent radiation therapy and chemotherapy for bulky stage IB2, IIA, and IIB carcinoma of the uterine cervix with proximal parametrial invasion. Int J Radiat Oncol Biol Phys 2008: 72:1508-1515.

26. Martinez-Monge R, Jurado M, Aristu JJ et al.: Intraoperative electron beam radiotherapy during radical surgery for locally advanced and recurrent cervical cancer. Gynecol Oncol 2001: 82:538-543.

27. Monk BJ, Tian C, Rose PG, Lanciano R: Which clinical/pathologic factors matter in the era of chemoradiation as treatment for locally advanced cervical carcinoma? Analysis of two Gynecologic Oncology Group (GOG) trials. Gynecol Oncol 2007: 105:427-433.

28. Houvenaeghel G, Lelievre L, Rigouard AL et al.: Residual pelvic lymph node involvement after concomitant chemoradiation for locally advanced cervical cancer. Gynecol Oncol 2006: 102:74-79. 
3 TABLE 1: Characteristics of the 35 patients who completed the study protocol 4

\begin{tabular}{|l|l|}
\hline $\begin{array}{l}\text { Age, mean } \\
\text { (range) }\end{array}$ & $50.0(33-75)$ \\
\hline $\begin{array}{l}\text { BMI, mean } \\
\text { (range) }\end{array}$ & $26.1(17.5-40.5)$ \\
\hline $\begin{array}{l}\text { Histology } \\
\text { SCC:AC }\end{array}$ & $33: 2$ \\
\hline IIA-bulky & 2 (6\%) \\
\hline IIB & $17(48 \%)$ \\
\hline $\begin{array}{l}\text { III-IVA } \\
\text { Tumor volume, } \\
\text { cm, mean } \\
\text { (range) }\end{array}$ & $4.5(3-8)$ \\
\hline $\begin{array}{l}\text { Positive pelvic } \\
\text { Lymphnodes } \\
\text { At imaging }\end{array}$ & 10 \\
\hline
\end{tabular}

5 Legend : BMI, body mass index; SCC, squamous cell carcinoma; AC, adenocarcinoma 6 
9 TABLE 2: Peri-operative and post-operative complications observed in the 35 patients who 10 completed the study protocol

\begin{tabular}{|l|l|l|l|}
\hline & Peri-operative & Post-operative & Total \\
\hline Lymphocoele & 3 & 3 & $6(17 \%)$ \\
\hline Pelvic Sepsis & 2 & 3 & $5(14 \%)$ \\
\hline $\begin{array}{l}\text { Urinary Infection } \\
\text { (pyelonephritis) }\end{array}$ & 3 & - & $3(8.6 \%)$ \\
\hline $\begin{array}{l}\text { Deep Venous } \\
\text { Thrombosis }\end{array}$ & - & 3 & $3(8.6 \%)$ \\
\hline Ureteral Fistula & 2 & 1 & $3(8.6 \%)$ \\
\hline Bladder fistula & - & 1 & $1(2.9 \%)$ \\
\hline Ureteral Stenosis & - & $\begin{array}{l}3(1 \text { requiring } \\
\text { nephrostomy) }\end{array}$ & $3(8.6 \%)$ \\
\hline $\begin{array}{l}\text { Necrotic Wound } \\
\text { Dehiscence }\end{array}$ & 2 & 1 & $3(8.6 \%)$ \\
\hline
\end{tabular}


16 TABLE 3: Pathological results of the 35 patients who underwent radical surgery

\begin{tabular}{|l|l|l|l|l|}
\hline $\begin{array}{l}\text { Treatment } \\
\text { response }\end{array}$ & $\begin{array}{l}\text { Positive } \\
\text { parametrium }\end{array}$ & Positive vagina & $\begin{array}{l}\text { Positive pelvic } \\
\text { Nodes }\end{array}$ \\
\hline $\begin{array}{l}\text { Cervical } \\
\text { remplete } \\
\text { response }\end{array}$ & $12(34 \%)$ & $0 \%$ & $1 / 12(8 \%)$ & $\begin{array}{l}3 / 12(25 \%) \text { one } \\
\text { also aortic } \\
\text { positive nodes }\end{array}$ \\
\hline $\begin{array}{l}\text { Cervical } \\
\text { microscopic } \\
\text { residual disease }\end{array}$ & $14(40 \%)$ & $3 / 14(21 \%)$ & $4 / 14(29 \%)$ & $1 / 14(7 \%)$ \\
\hline $\begin{array}{l}\text { Cervical } \\
\text { macroscopic } \\
\text { residual disease }\end{array}$ & $9(26 \%)$ & $\begin{array}{l}7 / 9(78 \%) \text { one } \\
\text { macroscopic } \\
\text { involvement }\end{array}$ & $2 / 9(22 \%)$ & $\begin{array}{l}5 / 9(55 \%) \text { two } \\
\text { also positive } \\
\text { aortic and one } \\
\text { positive inguinal } \\
\text { nodes }\end{array}$ \\
\hline & 35 & $10(28.6 \%)$ & $7(20 \%)$ & $9(26 \%)$ \\
\hline
\end{tabular}


FIGURE 1

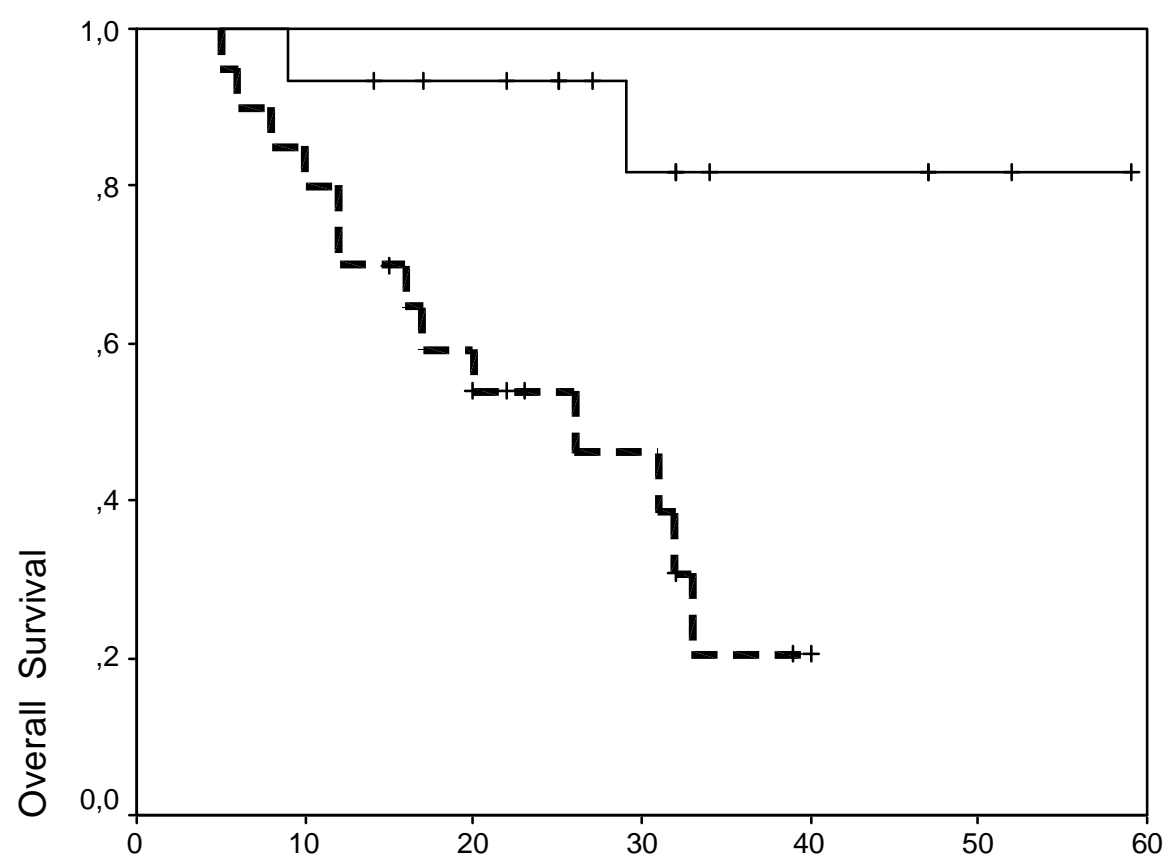

months 